\title{
Submeti um Artigo à Acta Médica Portuguesa. E Agora?
}

\section{Submitted a Paper to Acta Médica Portugal. What Happens Now?}

Tiago VILLANUEVA $\triangle^{1}$, Carla de SOUSA ${ }^{1}$, Pedro ESCADA ${ }^{1}$, Helena DONATO ${ }^{1}$, Miguel REIS ${ }^{1}$

Acta Med Port 2020 Feb;33(2):88-89 - https://doi.org/10.20344/amp.13373

Palavras-chave: Manuscritos como Assunto; Políticas Editoriais Keywords: Editorial Policies; Manuscripts as Topic

Em 2019, foram publicados 173 artigos na Acta Médica Portuguesa (AMP). Tendo em conta que recebemos um total de 1152 submissões - o maior número de sempre - temos de rejeitar a maior parte desses artigos sem sequer enviá-los para revisão por pares. Tentamos fazê-lo rapidamente para que os autores possam logo re-submeter o artigo a outra revista.

Todos os artigos submetidos à AMP são sujeitos a triagem inicial por um editor sénior, que emite habitualmente um parecer preliminar. Esta primeira avaliação é depois validada, ou não, pelo editor-chefe, responsável pela decisão de rejeitar um determinado artigo sem revisão por pares ou de o enviar para revisão por pares. Nesta fase, é por vezes necessário pedir também a opinião de um outro editor. Os artigos submetidos à AMP Student são habitualmente geridos pela equipa de editores júnior, com o apoio e supervisão do corpo editorial da AMP.

É importante salientar que rejeitamos muitos artigos por não cumprirem as normas de publicação da AMP, pelo que é essencial que os autores consultem as mesmas antes de submeterem o seu artigo.

Sempre que necessário, nomeadamente perante a existência de relações pessoais ou profissionais relevantes com os autores de um artigo, o editor-chefe (ou qualquer outro editor), declara a existência de conflitos de interesse em relação a esse artigo e pede a outro colega da equipa que se encarregue de tomar as decisões editoriais.

Cerca de $26 \%$ dos artigos submetidos são enviados para revisão por pares. O processo de "gestão" do artigo, que envolve contacto regular com os autores e alocação de revisores, é normalmente efetuado pela equipa in-house da AMP que inclui a coordenadora editorial e o assistente editorial. $\mathrm{O}$ esforço de redução dos tempos de processamento editorial e resposta a autores e revisores tem-se traduzido num processo editorial mais ágil. Para tal contribui também o hábito de solicitar aos autores que proponham nomes de possíveis revisores. Esta estratégia permite-nos por um lado diminuir o tempo até à decisão editorial e por outro expandir a nossa base de dados de revisores de forma regular e contínua. Qualquer médico, independentemente da fase da carreira em que se encontra, pode inscrever-se como revisor na nossa plataforma em https://www.actamedicaportuguesa.com/revista/index. php/amp/login. Dadas as características dos artigos submetidos e o rigor dos processos avaliativos, registamos necessidades permanentes de revisores de áreas como epidemiologia, estatística, nutrição, psicologia, economia e gestão, ética, etc. Temos ainda manifestamente dificuldade em recrutar revisores em algumas áreas, o que leva a que se verifiquem por vezes atrasos significativos no processamento dos artigos. É, por isso, importante termos o maior número de revisores registados de forma a reduzir-se o mais possível a probabilidade de se verificarem atrasos a nível dos tempos de decisão, pelo que renovamos o nosso apelo para que os nossos leitores se registem na plataforma como revisores.

Após um número suficiente de revisões consistentes de cada artigo, o editor-chefe (ou outro editor, em caso de indisponibilidade daquele), sozinho ou com o apoio de outros editores da sua equipa, toma a decisão de enviar o artigo para correções pelos autores, ou então de o rejeitar. Mesmo quando pedidas correções, não é garantido que se venha a aceitar o artigo, que poderá ser recusado numa etapa posterior caso sejam identificados problemas importantes com a nova versão do artigo ou os autores revelem dificuldades em responder de forma satisfatória aos comentários de revisores e editores.

Todas as decisões são tomadas com total independência editorial da Ordem dos Médicos, no âmbito de um processo editorial justo e robusto que salvaguarda a imparcialidade das avaliações.

Alguns artigos que são aceites para publicação na AMP acabam por ter ampla cobertura mediática em grande parte graças ao trabalho da Assessoria de Comunicação da Ordem dos Médicos, que produz e divulga comunicados de imprensa para os media. Temos noção que, em alternativa, alguns autores possam querer produzir e divulgar os seus próprios comunicados de imprensa através das suas instituições, mas nesse caso sugerimos que entrem em contacto connosco previamente para acertar uma data de embargo que coincida com a data de publicação online.

Somos contactados com muita frequência por autores que pretendem sondar o interesse da equipa editorial em publicar os seus artigos. As pre-submission inquiries são

1. Acta Médica Portuguesa. Ordem dos Médicos. Lisboa. Portugal.

$\triangle$ Autor correspondente: Tiago Villanueva. tiago.villanueva@ordemdosmedicos.pt

Recebido: 03 de janeiro de 2020 - Aceite: 03 de janeiro de 2020 | Copyright @ Ordem dos Médicos 2020 
uma boa prática editorial e permitem poupar muito tempo, quer aos autores quer à equipa editorial, evitando-se assim submissões cujo interesse reduzido se identifica logo à partida. Mas, mesmo nos casos em que depois da pre-submission inquiry encorajamos os autores a submeterem os seus artigos na plataforma, frisamos sempre que nunca podemos fazer promessas em relação à publicação, uma vez que a mesma terá que passar sempre pela revisão feita por revisores externos.

Procuramos seguir as melhores práticas editoriais internacionais, mas temos consciência que existe margem

\section{REFERÊNCIAS}

1. Brito D, Villanueva T, Sousa C, Nunes AB, Duarte S, Reis M. A perspectiva dos nossos leitores: destaques do primeiro questionário para modernizar, tornar mais eficiente, equipar a AMP para melhor comunicar com os seus interlocutores. Consideramos que para melhorar é muito importante analisar com atenção o feedback dos nossos autores, revisores e leitores, pelo que temos toda a disponibilidade para receber críticas construtivas em depeditorial@actamedicaportuguesa. com. $\mathrm{O}$ ano passado realizámos o primeiro inquérito aos leitores na história da AMP, e obtivemos resultados muito interessantes, que nos vão ajudar a oferecer um produto e serviços com mais qualidade em $2020 .^{1}$

aos leitores da Acta Médica Portuguesa. Acta Med Port. 2019;32:623-4 